\title{
Impact of Thinking Styles on Learning Functions in the Online Environment
}

\author{
Bouhnik Dan, Carmi Golan \\ Jerusalem College of Technology \\ Jerusalem, Israel
}

\begin{abstract}
In this study we examine the connection between thinking styles and learning function and satisfaction of students participating in academic E-learning courses. We also examined the connection between computer experience/skills and gender differences to these variables. The research included 188 B.A. students using the HighLearn system. The data was collected using questioners which examined thinking styles, prior experience with computer/internet applications, and views regarding on-line learning. Furthermore, interviews were held with a sample group of students. The research results show an influence of thinking styles on learning function, personal opinions and satisfaction. A positive influence was also found with regard to prior experience with computer/internet applications and gender. The results show that although virtual courses offer a variety of learning possibilities, these are utilized mostly by students with certain thinking styles. Gender and previous experience with computer/internet applications affect the amount of success in the virtual course.
\end{abstract}

\section{Introduction}

The constantly developing internet based environments have, in recent years, found their way into the educational system, Many institutions, from grade schools to colleges, if it be single vocational training courses or university degrees - have chosen to adopt various E-learning applications from the numerous existing and continuously developing programs.

The reasons behind this development are vast. According to Idan [13] the internet revolution paved new ways for learning. The availability of huge information warehouses and data bases [19] and the possibility to extract all types of information from them in a speedy and effective manner [15] introduce vast possibilities for educational enrichment. One of the greatest advantages of E-learning is the independency from time and place. One can study (or teach) any time and any place thus creating bridges between various populations and cultures which, in turn, enriches the exchange of information and knowledge [13]
Concepts which represent traditional learning, such as: classroom, textbook, teacher, students and contents take on new meanings as the educational system evolves in response to the technological developments and the changing needs of society [13]. Initially E-learning simply provided an alternative means of transferring information between students and teacher. However, on the personal level nothing had really changed. The first generation of E-learners did not discover the internet as a thinking tool, thus no changes took place in the thinking processes of the learner [14] However, today, as E-learning tools develop and change, more attention is paid to the user's individual needs, thus the development of new technological possibilities E-Textbooks, artificial intelligence, search engines and more [13], [14].

The quick integration of the internet and information technologies into educational systems instigated significant changes in learning frameworks and the application of new pedagogical strategies. The growth in the use of technologies and communication networks in courses in general and in academic courses specifically, raises the necessity of constant research of the factors which affect the effectiveness of instruction processes and learning utilizing these tools [1], [5], [20] and [22].

In 1999 The Institute for Higher Education Policies published a detailed report which included a number of recommendations for future research in the E-learning area. Rather than studying isolated courses, research regarding comprehensive academic courses programs was recommended. The report suggested examining which technologies are most effective for which activities, which technologies are most effective for which thinking styles and identifying the characteristics of the students who succeed in the E-learning environment.

As a rule, E-learning exposed both the teachers and the students to a new learning atmosphere, different from the familiar conventional system. Experience and research have shown that the technological aspect of the learning process is the least significant aspect, with relation to students' success in these courses, because as time passes the 
technological tools develop and solutions to various problems and difficulties are introduced [23].

Other studies on this subject concentrated on the elements of the instruction process which affect the success of the E-learning courses. Many mentioned the importance of the teachers experience with the computer applications as well as his attitude towards E-learning - his perception of the teaching task and the extent of his open mindness to new teaching methods [4], [11], [21]. Others discussed the significance of constructive teaching theories best fitting to the information technologies. [6], [9], [10], [23] all mention the importance of support and encouragement during the E-learning process in order to help the students acquire the new learning techniques which are required to succeed in the new environment. It is also noted that the type of course may affect the teaching strategies. Courses which are mainly about delivering information are very different from courses which attempt to teach skills and require constant drills. The level of interaction between the teacher and the student varies between the courses, hence another element to consider when constructing an E-learning course [23].

As opposed to the above studies, which focused on the pedagogical aspects, we wish to examine this issue from the student's aspect. It is obvious that online learning is not suitable for every type of student. Many studies have attempted to identify particular student characteristics and other factors that can be used to predict whether a student might succeed or fail to achieve satisfactory results in an Elearning course [6], [7], [11], [12], [15], [17] and [23]. Researchers such as Wan [26] found that prior experience with ICT and virtual competence were two influential factors that affected E-learning and had a positive influence on its' outcomes. Manochehrs' study [16] showed that learners with an assimilating or converging learning style achieved better results with E-learning. Banks' and Faul's findings [3] indicated that students' characteristics may play a larger part in learning outcomes than the venue in which the course is presented. Oterholms' study [18] results highlight the benefits of critical thinking - both of the instructor and of the student in the on-line environment.

Carmo [8] studied which type of activities can be used to support different learning styles in Elearning. When various dimensions of learning styles are taken into account the results differ. For example visual/active students most often provide graphic answers, while visual/reflective students prefer text. This means that the environment should be adaptable including problem solving activities; recorded lectures and discussions. For sequential students, a learning environment which presents information in a logical order is required. The global learners must also be considered by providing the grand picture or goal of the topic or problem. Sensory learners presented weak abstraction capacity which means that the environment should include a higher diversity of examples and data. The materials presented and used in activities should be a blend of concrete information and abstract concepts.

Similar to these studies, we also wished to examine how students function in E-learning courses and their positions regarding this type of learning. The study examined the affect of six thinking styles (based on the Sternberg self-emotional discipline theory) on their learning function, attitude to Elearning and satisfaction from the online learning environment. We also checked the influence of previous knowledge and experience of ICT skills on success, position and satisfaction as well as the affect of gender on these three variables.

\section{Methodology}

Thinking styles and personal learning characteristics are an area in educational psychology which the science community discussed well before the era of online learning. Humans, amongst them students, are differentiated one from another in their thinking styles, in other words - in the way they acquire knowledge, formulate ideas and behave in reality. Recognizing the thinking style (or the thinking style profile) of the students may help explain why certain educational activities are appropriate for one but not for the other. Studies show that styles are at least partially connected and none can be defined as absolutely "good" or "bad"; each may contribute to some degree to the acclimation to a specific task or situation and what contributes in one situation may not have any affect in another [2], [6], [24], [25]. In our study we chose thinking styles based on Sternberg's' [24] selfemotional discipline theory. This theory recognizes a thinking style as a preferred way of thinking. It is not an ability. It is the individuals' preferred way of using his abilities according to the situation or the task at hand. Sternberg's' theory includes 13 thinking styles, from which we chose 6 styles, which we consider the most significant to E-learning:

- Global thinking style - characterizes those who focus on the big picture, the abstract and generalization.

- Local thinking style - characterizes those who focus on detail and concrete examples.

- Extrovert thinking style - characterizes those who prefer working with others.

- Introvert thinking style - characterizes those who prefer to work alone.

- Liberal thinking style - characterizes those who prefer new and innovative ways over convention.

- Conservative thinking style - characterizes those who prefer doing things in a conventional manner and are afraid of change. 


\section{The Research Process}

The research population included 188 B.A. students, most in their first year, from the School of Education in Bar Ilan University. The study was carried out in the required statistics course "Quantitative Research", which was delivered in an asynchronic technological environment by means of the HighLearn system which is the technological platform for virtual courses in Bar Ilan University. Interaction in the course was through group discussions, e-mail, bulletin board, comments and reactions to the course and Help Desk for technological problems. The students also had access to the course text book and weekly frontal exercise classes were held regularly. The study process in the course was based on the 'Clarification through Multiple Representation' concept, which is appropriate for complex substances. The model is based on constructive learning; presentation of the contents is consistent; uses multiple forms of presentation; supports branched learning and encourages independent study. The learning process consisted of three parts: First part - knowledge items, SPSS, presentations; second part - practice; third part - assignments, enrichment. The evaluation exam consisted of multiple choice questions.

The quantitative data was collected using two questionnaires: a questionnaire which examined thinking styles and a questionnaire which examined knowledge of and previous experience with computer and internet applications, positions and satisfaction towards online learning. Furthermore, structured interviews were conducted with a sample group of 19 students, who constitute $10 \%$ of the research population. The research was carried out in two sequential stages. In the first stage, the quantitative questionnaires were distributed after the publication of the first semester's grades. The interviews were held during the second semester. All the participants completed both questionnaires.

\section{Research Results}

Analysis and examination of the results show that regarding some of the variables which were checked significant differences exist in function, positions and satisfaction among the students which were characterized by different thinking styles. Furthermore, significant differences were found in accomplishments, positions and satisfaction among students with prior knowledge of and experience with computer applications and internet skills and those students who lack previous experience. Also, significant differences were found between men and woman in grades, positions and satisfaction regarding learning in an asynchronic computerized environment.
The quantitative data shows significant differences between students who were characterized as having a liberal thinking style and those lacking this style. Students with a tendency towards the liberal thinking style tend to be less satisfied with the evaluation system and the average time they invest in the course is higher. Furthermore, differences were found between students with introvert thinking styles and those lacking this style regarding two out of the ten variables. Students with introvert thinking styles expressed higher satisfaction with the learning process and more positive positions regarding learning in the asynchronic computerized environment. Another significant difference was found between students with local and conservative thinking styles and those who lack these styles in one of the ten variables. The students with local or conservative thinking styles showed higher satisfaction with the evaluation system.

We did not discover any significant statistical findings regarding the relationship between thinking styles and the accomplishments in the course. However, the statistical tests clearly showed that students with more previous experience with computers and online courses received higher grades on the exam, have more positive positions regarding online learning and are more satisfied with the courses evaluation system. We also found statistical significance which points to the fact that students with more internet skills have more positive positions regarding learning in a computerized asynchronic environment and are more satisfied with the technological system.

However, as opposed to what we assumed, the quantitative test did not reveal significant gender differences in thinking styles. Nonetheless, according to the $\mathrm{t}$ test $(\mathrm{t}=-2.30, \mathrm{df}=19$, sign $=0.033)$ women express more positive positions regarding learning in an asynchronic computerized environment (AV = 2.79 compared to $\mathrm{AV}=2.36$ ). Also, further results of the $t$ test show $(t=-2.62, \mathrm{df}=16$, sign $=0.019)$ that women are more satisfied with the learning process $(\mathrm{AV}=3.85$ compared to $\mathrm{AV}=3.30)$ and the evaluation system $(\mathrm{AV}=3.82$ compared to $\mathrm{AV}=3.10)$ and their grade average is higher ( $\mathrm{AV}=83.02$ compared to $\mathrm{AV}=68.00$ )

We also found that the grade average in the course was 82.09 , a good average considering the unconventional program, the content of the course and its practical characteristics. As mentioned above, the female grade average was found to be higher. The grade range points to a relatively normal distribution, with about half of the students (48.8\%) receiving grades between 85 and 100 and about half the students receiving grades under 84 and only 7 failing the course. More than half the students $(55.9 \%)$ were satisfied with their grade. It should be noted that the satisfaction findings match the grade distribution. Despite the good grade average in the 
course, we found that most students prefer that the course be presented in a combined manner: half frontal in a classroom and half by E-learning on the internet (49.7\% frontal compared to $50.53 \%$ virtual). In other words, students prefer that more face to face meetings be integrated in the online course.

The structured interviews which were held at the end of the course with 19 of the quantitative survey population reinforced the statistical findings and enlightened other sides relevant to the entirety of causes and processes which affect the students' function in computerized learning. Through the interviews we identified two groups, almost equal in size: The one, 10 students, succeeded nicely in the computerized leaning. The second, 9 students, found this method very difficult. The students who succeeded in the course expressed positive opinions regarding the course and the computerized learning method. These positions were derived mainly from the ease of learning from the time aspect, interest and variety. Positive opinions were expressed also regarding the learning process, mostly relating to interest, challenge and innovativeness. On the other hand, students who experienced difficulty expressed negative opinions regarding the learning method, whose source is mostly the uneasiness of learning on the internet, difficulties coping with the study material to the point of not understanding the material. Furthermore, their negative opinions regarding the learning process as well, derived mostly from the discomfort of learning by computer, concentration difficulties and cumbersome accessibility to the tutors. While those who succeeded said that they would enroll in other such courses and would recommend doing so to their friends, most of those who found the course difficult noted that they would avoid such courses in the future and would not recommend them to their friends.

Among the students from both groups, about two thirds experienced difficulty with the learning material. About half these students stated that they have no command at all of the material, while the other half felt they had acquired partial command of the material. The remaining third expressed good command of the material. That said, most of the students from both of the groups pointed out the difficulty in applying the material on a practical level. The successful students expressed control over the progress pace, while those who had difficulties felt a lack of control, a feeling which was caused by their inability to comprehend the material and their inability to complete their tasks on time.

Most of the students who succeeded in the course stated that they had previous knowledge of and experience with computers and internet, as opposed to those who experienced difficulties in the course and noted that they had none or minimal prior experience. The qualitative research taught us that the interviewees from both groups felt that their achievements in the course did not reflect the effort that they made: some indicated that they put a lot of effort into the course but, nonetheless, did not succeed, and others pointed out that they did well with minimal effort.

Also supporting our quantitative findings is the preference of the students from both groups to combine, at least partially, traditional frontal classroom meetings. About two thirds of those students who experienced difficulties stated that they would have preferred that the course be taught in the traditional manner and felt that they would have done better if that had been the case, while half of the successful students preferred the E-learning system. Most of the students from the group that found the E-learning course difficult felt that they would have succeeded better if at least part of the course were transferred in the traditional frontal manner.

To summarize the findings, in our study we found significant differences between students with a liberal thinking style and those lacking this style with regard to two of the variables which were examined - success and positions. Also significant differences were discovered between students with introvert thinking styles and those lacking this style, with regard to the satisfaction variable and the position variable. Another significant difference was found between those with local or conservative thinking styles and those lacking these styles, with regard to the satisfaction from the evaluation system. Regarding gender differences, differences exist in the satisfaction and position variables but not in the success variable. Significant positive ties were discovered between the level of prior knowledge and experience and success, positions and satisfaction from the course. This finding was also supported by the interviews which brought to light the difficulties experienced by not a small number of the participants. These difficulties derive mostly from their lack of prior knowledge of and experience with the learning system. These difficulties were expressed clearly in their positions and level of satisfaction with the course.

Table 1 describes the statistical connection between the variables which received positive results and thinking styles, prior knowledge of and experience with computers and internet applications and students' function variables, positions and satisfaction. 
TABLE I. The Connection Between Variables and Thinking Styles

\begin{tabular}{|l|l|l|l|l|l|l|l|l|}
\hline $\begin{array}{l}\text { Research } \\
\text { Variables }\end{array}$ & Global & Local & Extrovert & Introvert & Liberal & conservative & $\begin{array}{c}\text { Computer } \\
\text { Knowledge }\end{array}$ & $\begin{array}{c}\text { Internet } \\
\text { Applications }\end{array}$ \\
\hline Achievements & & & & & & $0.15^{*}$ & & $0.17^{*}$ \\
\hline Effort (time) & & & & $0.19^{* *}$ & & & \\
\hline $\begin{array}{l}\text { Position regarding } \\
\text { learning } \text { in virtual } \\
\text { asynchronic } \\
\text { environment }\end{array}$ & & & & & & & & \\
\hline $\begin{array}{l}\text { Satisfaction with } \\
\text { learning process }\end{array}$ & & & & $0.16^{*}$ & & & & \\
\hline $\begin{array}{l}\text { Satisfaction with } \\
\text { evaluation method }\end{array}$ & & $0.14^{*}$ & & & & $0.14^{*}$ & \\
\hline $\begin{array}{l}\text { Satisfaction with } \\
\text { technological } \\
\text { system }\end{array}$ & & & & & & & $0.14^{*}$ & \\
\hline
\end{tabular}

\section{Discussion}

The results of the study clearly show that Elearning internet courses are not appropriate for all students. We found a high variance between the students participating in the course: A large group succeeded nicely, however, quite a few experienced difficulties. The results, from both the quantitative and qualitative research, clearly showed that, although the virtual course on the internet offers more learning possibilities than formal learning, these possibilities are utilized by students with certain characteristics more than others. Out of the six thinking styles, among four - liberal, introvert, local and conservative - variances were evident between those who have one of these style types and those who are lacking one style or the other. We saw that students with these thinking styles - liberal, introvert, local and conservative - gain the most from a nonconventional learning process, while those lacking one of these styles gain less from the Elearning system.

We found that students with liberal thinking styles make more of an effort in the course because they like doing things in new and different ways. A student with this thinking style benefits from this type of course because it challenges him and offers him knowledge in a new manner. For the same reasons, such a student appreciates the change in the evaluation system as well.

We also saw that students with introvert thinking styles reveal positive tendencies to learning from a distance and expresses satisfaction from the instruction process because he prefers studying on his own. The individual nature of learning in an online course corresponds to his being self-centered, thus he benefits from this type of learning. Apparently students with local thinking styles tend to appreciate the evaluation system because he likes tangible details and concrete issues. The study material and the nature of the specific statistics course, as well as the evaluation system in the form of short multiple choice answers, correspond to his preference of detail and actual examples. As to those with a conservative thinking style, the evaluation system suits him, because he likes to do things in a customary and safe manner. Multiple choice questions, as an evaluation tool, which demand memorization, corresponds to his preference of the conservative manner of studying.

Both the quantitative and qualitative data revealed that prior knowledge of and experience with computer applications and previous experience with virtual learning are a basic conditions for success in an E-learning type course. Also here we found that the students' function in the course, their position regarding asynchronic E-learning, their satisfaction from the instruction process, the evaluation system and the technological system are directly affected by the level of prior personal knowledge of and experience with computer and internet applications. Gender also affects the learning process. We found that women hold more positive positions regarding the instruction process and the evaluation system and their grade average is higher than men.

\section{Conclusions}

The research results show that complexity of the instruction method and the learning process of Elearning courses, combined with the absence of experience with information technology applications and communication environments, raise quite a few challenges for many students, thus damaging the existing potential of the method. The research's conclusions point to the fact that there is no online course which is appropriate for all students. A variance exists among the students regarding 
thinking styles and experience with computers and internet, which affects function, position and satisfaction.

The results of the research bring us to the conclusion that, although the virtual course offers various learning possibilities, these may be utilized most by students with certain thinking styles. Regarding four of the tested styles - liberal, introvert, local and conservative - variances were evident between those who have one of these style types and those who are lacking one style or the other. We saw, that those with liberal or introvert thinking styles, benefit from the unconventional learning method, while the local and conservative thinkers find the traditional evaluation system suitable for them.

Another conclusion which arises from the quantitative research and is supported by the qualitative research -experience with computerized environments and prior knowledge of computer and internet applications are cardinal foundations for success in the virtual course. We found, that the level of experience the students bring to the class directly affects their function in the course, their positions regarding distant learning, their satisfaction with the instruction process, the evaluation method and the technological system. Furthermore, we found that gender differences affect the learning process and results. We found that women hold more positive positions regarding the instruction process and the evaluation system and their grade average is higher than men.

\section{Summary}

E-learning is a new method of acquiring knowledge and education. This method is still in the process of formation and change. Nonetheless, this field is maturing in a number of fields: technology, methodology, pedagogy and organizational. The system meets a number of existing needs: economic, organizational, social and personal and allows the utilization of new educational opportunities. The continuing improvement of the capabilities of the system - tools, as well as network speed - enables educators to depend on the internet as part of the an educational environment in many educational frameworks, higher education included.

The results and the conclusions of the research show that E-learning courses do not suit all of the student population. Educators and speakers should be aware of the various thinking styles when constructing and while teaching the course. Characterization and classification of thinking styles of students who succeed with E-learning; stipulating certain computer skills for participation in technology integrated courses: offering the choice between online courses and frontal classes; computer workshops for students who need to improve their computer skills - all these could significantly contribute to students' integration and success in Elearning courses. It is recommended to utilize as many technological applications as possible in computerized courses in order to allow flexibility and variation of the instruction methods, assignments and evaluation systems in a manner which will be appropriate for a wider range of students.

We hope that the results of this study and its conclusions will help increase the awareness to the gaps which exist in the population of learners and to their various needs and to a better understanding of the factors which affect the affectivity of the studying and success rate of the students using the Elearning method.

\section{References}

[1] L. Arp, B. S. Woodard and L. Mestre, "Accommodating diverse learning styles in an online environment", Reference \& User Services Quarterly, vol. 46(2), pp. 27-32, 2006.

[2] H. Astleitner and R. Steinberg, "Are there gender differences in web-based learning? An integrated model and related effect sizes", Association for the Advancement of Computing in Education (AACE), vol. 13(1), pp. 47-63, 2005.

[3] A. Banks and A. Faul, "Reduction of face-to-face contact hours in foundation research courses: Impact on students' knowledge gained and course satisfaction", Social Work Education, vol. 26(8), 780-793, 2007.

[4] C. J. Bonk, A. J. Cumming, N. Hara, \& B. R Fischler, A Ten Level Web Integration Continuum for Higher Education: New Resources, Partners, Courses, and Markets, $1999 . \quad$ Retrieved: http://php.indiana.edu/ cjbonk/paper/edmdia99.html

[5] D. Bouhnik and G. Carmi, "E-course: ICT Elements and Students' Thinking Dispositions", JIT- i-manager's Journal on Information Technology. Sep-Nov 2012, Vol. 1(4). pp.19-33, 2013.

[6] D. Bouhnik and T. Marcus, "Interaction in distancElearning courses", Journal of the American Society Information Science and Technology, vol. 57(3), pp. 299305, 2006.

[7] J. M. Carey, "Effective student outcome: A comparison of online and face-to-face delivery modes", DEOSNEWS, vol. 11(9), ISSN pp. 1062-9416, 2001.

[8] L. Carmo, A. Gomez, F. Pereira and A. J. Mendez, "Learning styles and problem solving strategies", Proc. of the 3rd E-learning conference - Computer science education, Coimbra, Portugal, 2006.

[9] M.A. Cavanaugh, G.T. Milcovich \& J.Tang, The Human and Technical Dimensions of Multimedia Distance Learning (MDL): A Study of MDL Effectiveness in 
Global Human Resource Management Class. Working Paper Cornell University, 2000.

[10] C.C. Chou, Model of Learner-Centered ComputerMadiated Interaction for Collaborative Distance Learning. University of Minnesota. ERIC Clearinghouse on Information \& Technology, 2003.

[11] C. Gunn, "Effective online teaching - How far do the framework go?", School of Education, University of Auckland, New Zealand, 2003. Available: http://www.distance-educator.com

[12] L. Harasim, "Shift happens online education as a new paradigm in learning", The Internet and Higher Education, vol. 3(1-2), pp. 41-61, 2000.

[13] A. Idan, E-learning - Future of learning and institutions, Eureka, 14, 2001.

[14] A. Idan, E-learning and Knowledge Management, 2003 Retrieved: http://www.the21century.com/KMEL.htm

[15] B. H. Khan, "Discussions of E-learning dimensions", INTERVIR - Online Journal of Education, Technology and Politics, 2001.2 Retrieved: http://www.intervir.org/n1/khan/k1_e.htm

[16] N-N. Manochehr, "The influence of learning styles of learners in E-learning environments: An empirical study", Information Systems Department, Qatar University. CHEER, vol. 18, pp. 10-14, 2006.

[17] R. E. Mayer, Multi-media learning. New York: Cambridge University Press, 2001.

[18] I. Oterholm, "Online critical reflection in social work education", European Journal of Social Work, vol. 12(3), 2009.

[19] R. D. Owsten, The World Wide Web: A Technology to Enhance Teaching and Learning? Educational Researcher 26(2), 27-33, 1997.

[20] M. Resnick, "Rethinking learning in the digital age", In Kirkman, G. (Ed.) The Global Information Technology Report: Readiness for the Networked World. Oxford University Press, 2002.

[21] H. M. Rossman, Successful Online Teaching Using An Asynchronous Learner Discussion Forum. Asynchronous Learning Networks,3,1999 Retrieved: http://www.aln.org/alnweb/journal/Vol3_issue2/rossman.h tm

[22] F. Saba, "Distance education: Covering distance education since 1995", 2001. Retrieved: http://www.distance-educator.com/portals

[23] G. Salamon, "Technologies and education in the information era". Haifa University Publications, 2000.

[24] R. J. Sternberg, "Thinking styles: theory and assessment at the interface between intelligence and personality" In R. J. Sternberg \& Ruzgis, P.(eds.),
Personality and Intelligence. Cambridge University Press, 1994.

[25] R. J. Sternberg, "Thinking styles" NY: Cambridge University Press, 1997.

[26] Z. Wan,Y. Wang and N. Haggerty, "Why people benefit from E-learning differently: The effects of psychological processes on E-learning outcomes". Information \& Management, vol. 45, pp. 513-521, 2008. 